\title{
Application of Computer in Track and Field Athletics Management
}

\author{
Li Chunlin ${ }^{1}$ a JinLei*2b \\ 1.Ji'nan Unviersity, Sports Department Guangzhou 510632 \\ aemail:454622113@qq.com \\ 2.The Student Physical Health Institute of Henan University Kaifeng 475001) \\ bemail:jlei636982@163.com \\ *JinLei is Corresponding Author
}

Key words: athletics, athletics, computer programming

\begin{abstract}
This paper discusses how to apply the advantage of the computer to complete the management work of the track and field athletics, and make the management work more scientific and systematic, and apply the successful experience of the management to expound it theoretically.

The track and file athletics is one of the major approaches for pushing forward the public sports, with extensive publicity. Therefore, how to scientifically manage this athletics is an important subject for us. Hold a track and field athletics as usual, organize people to program and copy the program before the athletics, and proceed with other related work. It is quite time consuming and labor consuming. Besides, it is easy to cause errors. In addition, it takes long time to finish the layout and printing. The cost is also so high. During the competition, it is necessary to arrange several people to do the copying and make statistics on the scores. If the sheet is not filled in correctly, the statistics work is quite easy to cause errors, which will bring inconvenience to the whole management.

That the computer technology is brought into the sports scientific domain brings bright prospect for the management of the sports. It is easy to use and brings accurate statistics, which can save much time and labor. Therefore, it has become a powerful tool for the management of the track and field athletics. Gradually, it has aroused great concern among the sports workers. This paper focuses on how to apply the advantage of the computer to finish the management of the track and field athletics, and make it achieve scientific development, and then discusses our experience in the development application.
\end{abstract}

\section{System function design}

System design concept

Firstly, we have visited many experts and users. Based on the literature we have reviewed, we think that the design of the whole software system should focus on how to give full play to the advantage of the computer and take replacing the labor with complex process as the dominant thought. Namely, it is necessary to expand the systematic function as much as possible, and consider that most operators are not engaged in the computer, so it is necessary to adopt the interactive mode and reduce the operation process as much as possible, and conduct the prompting operation.

System function design content

With regard to applying the computer management, firstly, it is necessary to understand people's understanding of this work, and formulate the language programming that the computer can understand. Before programming, it is quite important to design the function of the content to be managed. The track and field athletics is a big complex system, especially the basic track and field athletics. Due to its own feature, this system becomes more complex. Therefore, when we 
developed this management software system, we should consider the normality of the big sports meeting and also the feasibility of the basic track and field athletics. For this reason, we have designed 9 functions and 52 subsystems in the aspect of the function selection. (See function framework)

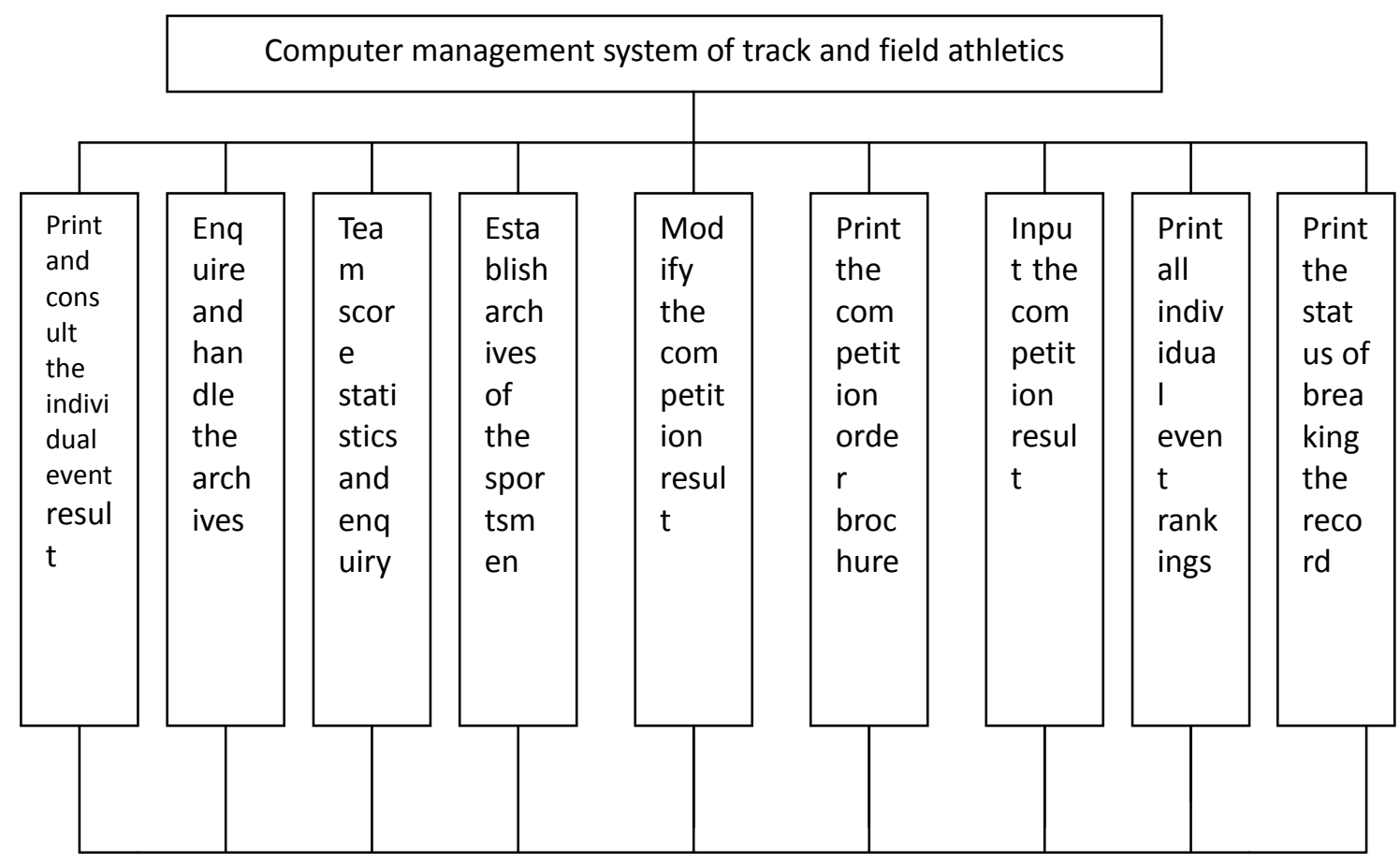

Function framework

Data structure design of the system

Archives design of the athletes

The archives design of the athletes is a database established according to the application form of each unit, which is divided into two databases. (a) Archives are established for conveniently inputting the archives of the athletes, including the number, name, unit, gender, group project 1 , project 2, project 3, project 4, and project 5. As general track and field athletics allow an athlete to apply for 3 items at most, and if with the relay program, there should be 5 items at most, 5 fields are established in the project. The archives can be input with the information of the athletes in one time. (b) The result base is to provide convenience for the computer to search for the athletes during the competition rapidly, and it is generated through the archives automatically. It includes number, name, unit, gender, group and project. In this base, the purposes are arranged orderly and regularly. Data and file recording form

The identifier (key words) is before each recording. It is composed of pinyin of Chinese. The order is as follows:

DA DBF (archives)

No. Name

$\mathrm{BH} \quad \mathrm{KM}$

Unit

DM

Gender

XB

Group

$\begin{array}{lrrrr}\text { Project 1 } & \text { Project 1 } & \text { Project 2 } & \text { project 3 } & \text { Project 4 } \\ \text { XM1 } & \text { XM2 } & \text { XM3 } & \text { XM4 } & \text { XM5 }\end{array}$

CJK DBF (Results )

$\begin{array}{lccrrr}\text { No. } & \text { Name } & \text { Unit } & \text { Gender } & \text { Group } & \text { Project } \\ \text { BH } & \text { XM } & \text { DW } & \text { XB } & & \text { ZB }\end{array}$


DW DBF (Units )

No. Unit Group Total scores of the male Total scores of the female Total scores of male and female $\begin{array}{llllll}\mathrm{BH} & \mathrm{DW} & \mathrm{ZB} & \mathrm{N} 1 & \mathrm{~N} 2 & \mathrm{~N} 3\end{array}$ $\begin{array}{ccc}\text { Recordings of male } & \text { Recordings of female } & \text { Recordings of male and female } \\ \text { N5 } & \text { N6 }\end{array}$

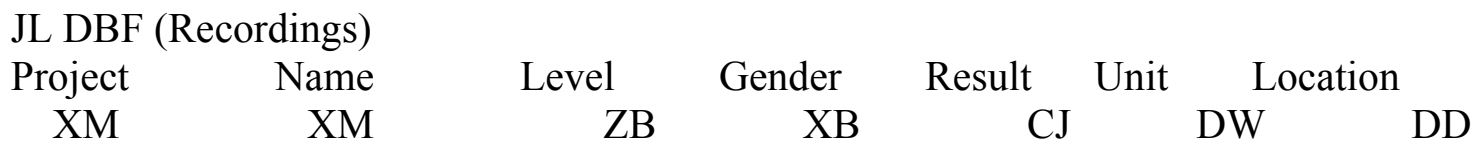

\section{Grouping confirmation}

Do the grouping according to the competition level of the sports meeting and the actual status of each unit. The number of he groups is not limited.

Realization of the system function

According to the above design concept and function design method, we have developed Computer Management System of Track and Field Athletics. Each function is as follows:

Print and inquire each individual event result

During the sports meting, the committee should always inquire the items and athletes recorded in the computer. Only if the consulted item number, gender and group number are input through this function, it will be feasible to print all competition situations of the enrolled athletes of this item (shown in the form of the individual result report sheet).

Inquire and handle the archives

Inquire the archives

During the competition, as the athletes' competition archives have been sent to the computer before the competition, when the result is received, it is common that we cannot consult the athletes. At that time, only if the number of the athletes is input into the computer, all items that the athletes participate in can be obtained. If the athlete does not report this item in the archives, the judge can be invited to determine whether to cancel the athlete's competition result in this item.

Handle the archives

As all items that the athletes attend in the archives are arranged irregularly, it is inconvenient for inquiring the information rapidly in on-the-spot competition. Therefore, through this function, it is feasible to automatically make the archives generate the result base used by the competition. At that time, each item is arranged regularly in succession, which provides rapid and convenient inquiring conditions to input the athletes' results for on-the-spot competition.

Statistics and inquiring of the total scores of the group

Statistics of the total scores of the group

It is an important work in the management of the track and field athletics. It requires the statistics to be rapid and accurate. If the competition is over, it is necessary to get the total scores of the groups in each group. To overcome the slow computation of dBASE - III language, and improve the statistics speed, this system adopts storage variable file form, i.e. apply three different groups:

$\mathrm{X} 1 \mathrm{X} 2 \mathrm{X} 3---\mathrm{Xi}---\mathrm{Xn}$ - - Total scores of male group

Y1Y2Y3---Yi----Yn- -Total scores of female group

Z1Z2Z3----Zi----Zn- - Total scores of male \& female group

In this way, once the competition is over, the total score sheet of the group can be printed out.

Inquire the total score of the team

During the sports meeting, each unit should see about the total score of the group. Through this function, it is feasible to get the total score of female, male, and female \& male of any unit, as well as the stuatus of enrolling the athletes. 
Establish athlete archives

Apply the computer to manage any things. Firstly, there should be management content. As for the track and field athletics, the computer mainly manages the athletes. Therefore, to establish the athlete archives is an important fundamental work of this management system. It will directly influence the function quality of the whole system. As the application sheet of the athletes is focused on the Chinese characters, the input speed of the characters is relatively slow. To improve the input speed, we apply dBASE - III language. ( Set Carry on ) enables all same fields to be replaced mutually, which greatly reduces the repeated work. As for the input of the items the athletes apply for, all are replaced by the English characters. In this way, it can reach the purpose of the rapid input.

Modify the competition result

In the track and field athletics, especially the basic athletics, due to various reasons, it is common to modify the established rankings and total scores. The design of this function greatly meets this demand. It includes the modification based on the following two situations. The first one is that, after the competition, when the ranking and the total score should be changed, only if the rankings of the athletes who are judged recently, it will be feasible to print the amended result reports. Meanwhile, the total scores of the team will be increased and decreased automatically, so as to reach the purpose of the modification. The second one is that, when some competition ends up, when some athletes' rankings and total scores should be changed, only if the unit number is input, the total score of this unit can be presented. At that time, the moving cursor is only needed to do the modification.

Print the competition order brochure

Organize track and field athletics. With regard to the sports, it includes two parts. One is the work during the competition, and the other one is the competition brochure programming before the sports meeting. This work is quite labor and time consuming. Besides, it will take more time and workload to work on the arrangement of the competition schedule, competition grouping, representatives' lists, statistics about the number of people constituting the representative team, the highest recording of the sports meeting, etc. It increases much burden and the errors on the characters are relatively big. This function can well finish the work above. From the competition schedule arrangement to the highest recording sheet printing, all of them are automatically completed by the computer according to the rules of the track and field athletics. Reduce the labor and printing cost, and then enable the computer management to form a complete connected system from the pre-competition, mid-competition to the post-competition, which is a remarkable symbol of the scientific management of the track and field athletics. This function includes 5 subsystems: a. print the list of the athletes involved in all sports; b. print the list of the representative teams; c. competition grouping; d. statistics on the number of people in each representative team; e. print the highest recording sheet.

Input the competition results

According to the rule requirements of the track and field athletics, to input the competition results has three situations: order competition, quarter-final, and final. This function inputs the competition results as per these three situations. The input method is to input the number of the competition only. Such method can greatly improve the input speed during the competition being attended. When the athletes' results are input, the computer automatically sends the scores to the total score and rankings of each unit. Then, it prints the result reports as per the quantity that the users require to print. If same rankings and scores are encountered, add the symbol of recording breaking on the remark column automatically. The input of an item can be finished in a minute on average.

Print the summary sheet of the individual event rankings

In the track and field athletics, the committee usually needs the summary sheet of all individual event rankings, so as to send them to each unit promptly and keep recording. This function can print the summary sheet of the lists and rankings of different groups as per the users' requirements at any time. The sheet format is as per the individual result sheet of the formal sports meeting. 
Print the status of breaking the recordings of this year

The track and field athletics for each time has new results replaced by the original ones, which requires the computer to make statistics on the status of breaking the recordings when getting the total scores. The function can finish this task through three situations as per the demands of the sports meeting. The first one is to print the good news of breaking the records, and apply the way of the printing in the form of the literary language at any time, and then pass on it to the announcer, and issue it promptly. The second one is to completely print the list of the athletes who break the recordings in this competition in the form of literary language according to the demands for the general judge to announce the lists of breaking the recordings when the sports meeting ends up. The third one is to print the comparison statistics of this competition on the recording breaking items, athletes' names, units, and results.

\section{System usage result}

After this system goes through the trial running, the function is gradually improved and the system operates reliably. It proves that this system is fully in line with the design requirements of the track and field athletics. Through the practice, it demonstrates that:

Complete functions: this system can form one package service from the programming and printing of the order brochure before the sports meeting to the statistics work during the sports meeting, which can meet the requirements of the athletics.

Convenient usage: This system procedure applies a soft disc which can submit operation according to the menu form, and then goes through the computation and form printing. Each operation step is promoted by the Chinese characters. Therefore, the users can easily master it.

Easy to be modified: this system adopts modularized program structure. The structure is rational and clear, and the functions are reasonably divided. Therefore, it is quite easy to carry out the modification, which is easy to be expanded.

High output quality: This system can clearly output various sheets (all output sheets are based on the formal sheet forms) and screen presentation.

Flexible statistics and rapid speed: As the system adopts the form of storing the variable files and overcomes dBASE - III Language. The disadvantage is that the computation speed is too slow. Once the competition program is over, it is feasible to print the total scores of the female, male, and female \& male. Meanwhile, it will be convenient and rapid to modify the competition results during the sports meeting.

High economic efficiency: apply this system to formulate the order brochure cost, which is about 5 times as low as composing the brochure.

Broad application: applicable to various track and field athletics in the provinces and cities.

\section{References}

[1] Chen Lijuan. Application of Microcomputer in Track and field Athletics Arrangement and Recording of General Schools [J]. Journal of Being Sport University, 2009 (1): 87-89.

[2] Shi Jimin, Tang Guanquan. Visual Foxpro and Its Application System Development [M]. Beijing: Tsinghua University Press, 2000: 160-203.

[3] Fu Derong. Principle and Method of CAI Courseware Design [M]. Beijing: Higher Education Press, 1999.

[4] Puer - Lang, etc. wrote. HE Xu, etc. translated. Micro-computer User's Guide: Beijing Publishing House.1985.

[5]. School Physical Education. 1983. People's Sports Publishing House. 